\title{
Growth of E-commerce in India: An Analytical Review of Literature
}

\author{
Madhurima Khosla ${ }^{1}$, Harish Kumar ${ }^{2}$ \\ ${ }^{1}$ (Day Scholar, Shri Ram College of Commerce, University of Delhi, New Delhi) \\ ${ }^{2}$ (Assistant Professor, Shri Ram College of Commerce, University of Delhi, New Delhi)
}

\begin{abstract}
E-commerce is one of the fastest growing segments in the Indian Economy. Though marked by high growth rate, the Indian e-commerce industry has been behind its counterparts in many developed and emerging economies, primarily due to a relatively low internet user base. In a study conducted by global management consultancy firm AT Kearney in 2015, there were only 39 million online buyers in India; a tiny fraction of the 1.2 billion who live in the country. However, increased technological proliferation combined with internet and mobile penetration, presents a favorable eco-system for the development of e-commerce in India. The country is currently at the cusp of a digital revolution. Launch of $4 G$ services and decline in the tariffs of data plans and prices of data cards/USB dongles have reduced the cost of ownership of an effective internet connection. Availability of low cost smart phones and the extension of internet and broadband to the remotest corners will boost the augmentation of the internet user base, effectively bridging the gap between potential online buyers and actual buyers. The demographic dividend of the country also seems to encourage and favor the growth of $e$ commerce. The survival of the e-commerce firms in a highly dynamic environment becomes a challenging task when coupled with the cutthroat competition prevailing in the sector. The onus then lies on the firms to constantly adapt and innovate while providing an information rich and seamless experience to ensure customer loyalty. This study attempts to explore the evolution of e-commerce in India and identifies various challenges to as well the factors responsible for the future growth and development of e-commerce.
\end{abstract}

Keywords: B2B, E-Commerce, Indian Context, Literature Review

\section{Introduction}

"E-commerce is the use of electronic communications and digital information processing technology in business transactions to create, transform, and redefine relationships for value creation between or among organizations, and between organizations and individuals. "(Chanana \& Goele, 2012). In simpler terms, ecommerce is the extension of traditional business operations to electronic space. Regarded as the most promising application of information technology, it has enabled the businesses to augment their internal efficiency and to expand their operations globally, thus, surpassing geographical barriers.

As noted by Numberger \& Renhank (2005) in "The Future of B2C E-Commerce", absence of a precise and sustainable definition of e-commerce has led to a lack of consensus on quantitative estimates of e-commerce. While there is an agreement about the importance of various aspects of e-commerce, they are conceptualized differently. Thus, there is a lack of generally accepted definition, one which has a holistic overview of ecommerce. Most popularly, it is understood as the exchange of goods and services through an electronic medium.However, the utility of e-commerce is not limited to just sale and purchase of goods and services over computer networks,but, entails "the entire online process of developing, marketing, selling, delivering, servicing and paying for products and services." (Rina, 2016).

Categories of E-commerce -Based on the parties involved in the exchange, e-commerce has been categorized into the following applications -

B2B (Business to Business) - It encompasses all the electronic transactions between two organisations. Dealings between industrialmanufacturers and distributors, partners, wholesalers and retailers, i.e every exchange which involves businesses at both the ends, comes within the spectrum of B2B e-commerce.

B2C (Business to Consumer) - Though, the size of B2B e-commerce is almost six times the size of B2C in India, and is expected to reach $\$ 700$ billion by 2020 (Shankar, 2016), it is the idea of B2C that an average customer holds with respect to e-commerce transactions.It involves the sale of goods and services by a vendor to the end consumers, through a website utilizing shopping cart software.

C2C (Consumer to Consumer) -It includes all transactions of goods and services between consumers and doesn't form a significant portion of e-commerce. For example, an online portal can be provided by a third party like ebay, which can be used by consumers to put secondhand goods for auction or conduct other transactions.

C2B (Consumer to Business) - Like B2C, C2B model also involves the interaction between business and consumers but with their roles reversed; it is the consumer who creates value for the business and gets paid for the same. 
B2G (Business to Government) - It involves interaction between business and public sector via internet technologies, for the purpose of licensing and tax procedures and other government related opeartions. The size of B2G in e-commerce market is insignificant. E-commerce in India has seen tremendous growth in the recent years, especially, in the B2C segment, thriving on various advantages like convenience, time saving, easy comparison and feedback, availabitiy of options and comparitively low prices, over the traditional business. (Franco \& S, 2016). According to a research by Forrester, a leading global research and advisory firm, the ecommerce market in India was estimated to grow the fastest within the Asia-Pacific Region at a CAGR of over 57\% between 2012-16. The report, titled "Asia Pacific Online Retail Forecast, 2011 To 2016," had been issued by Forrester Research Inc. Analyst Zia Daniell Wigder, with Steven Noble, Vikram Sehgal and Lily Varon. (Chanana \& Goele, 2012).

The recent surge in the number of online vendors, big as well as small, favourable demographics (currently, $75 \%$ of the internet users are in the age group of 15 to 34 years and thus, are more integrated to ecommerce), launch of $4 \mathrm{G}$ services and decline in the tariffs of data plans and prices of data cards/USB dongles, availability of low cost smart phones and the extension of internet and broadband to the remotest corners of the country, together herald innumerable prospects for the development of e-commerce in India. The purpose of this project work is, to review the literature on e-commerce and thus, trace its development and also to find out trends that shall propel the growth of e-commerce in future, in India. The project contains an introduction to ecommerce and the lack of a universally accepted definition, its categorization into different applications and the prospects for the robust development of e-commerce in India. The introduction is followed by a review of literature available on different aspects of e-commerce which is analysed in the later segment with a view to find out factors that shall drive the growth in future.

\section{Review of Literature}

Gupta (2014) in her paper "E-Commerce: Role of e-commerce in today's business", presents a comprehensive definition of e-commerce while isolating it from e-business. The paper enlists the different ecommerce models i.e. B2B, B2C, B2G and C2C, narratively analysing the nitty gritties of each. Rina (2016)also elaborates the different applications of e-commerce in "Challenges and Future Scope of Ecommerce in India", at the same time, defining the degree to which they are operational in the country.

Gunasekaran, Marri, McGaughey, \& Nebhwani (2002) give a broad outlook of electronic commerce within organisational systems in "E-commerce and its impact on operations management", defining it with reference to e-trading and elaborating- how it has permeated every field of business. The paper identifies the revolutionary role played by earlier internet applications like e-mail and eletronic data interchange and details the revolutionary changes brought by the internet technologies in manufacturing, marketing, purchasing, design, production, selling and distribution, warehousing and human resource management. Internet based technologies have enabled businesses to shorten development, purchase and procurement cycles, maintain upto date product and market information, significantly increase the speed of communications and increase the quality of customer relationships by facilitating close contact and constant communication. The paper studies in depth, the significance of web based technologies in different business operations, thus, improving their efficiency through effective B2B e-commerce.

Mishra \& Kotkar(2015) trace the timeline and development of B2C e-commerce in "A Study on Current Status of E-Commerce in India: A Comparative Analysis of Flipkart and Amazon"with its inception in the mid 1990s through the advent of matrimonial and job portals. However, due to limited internet accessibility, weak online payment systems and lack of awareness, the progress was very slow. The Indian B2C e-commerce industry got a major boost in mid 2000s with the expansion of online services to travel and hotel bookings which continue to be major contributors even today.Das \& Ara(2015) observe in "Growth of E-Commerce in India"that though online travel and hotel bookings still control the lion's share of e-commerce market, their share has comparitively fallen over the years due to the recent augmentation and consequent rise of e-tailing services. There has been a tremendous surge in the volume of investment in this sector. With the e-commerce markets in the west reaching their saturation, investors see tremendous potential in the Indian market, in the light of which, many start ups have received funding from venture capitalists and private equity firms.

China's Alibaba Group and affiliate Ant Financial became the largest shareholders of One97 Communications, the parent of Indian e-tailer Paytm, by investing $\$ 680$ million, in 2015 (Aulakh, 2015). To tap the potential of what it regards as "underdeveloped internet economy" of India, Japanese investment company and technology powerhouse Softbank invested \$627 million into online retailing marketplace Snapdeal and $\$ 210$ million in Ola cabs. (Mac, 2014). Similarly, New York firm Tiger Global Management has funded companies such MakeMyTrip, Flipkart, Myntra and Quickr. The availablity of funds has presented a favourable ecosystem and growth opportunities for big as well as small companies. It has enabled local startups to survive in cut throat competition against foreign giants and has facilitated the penetration of e-commerce to every facet 
of human life; such that the differntiation between e-commerce and traditional buisness is getting blurred.(Aggarwal, 2014).

Through "Probles and Prospects of E-Commerce", Raghunath \& Panga (2013) present a comprehensive analysis of various nuances of e-commerce while accentuating that, in present time every business activity, be it advertising, ordering, payment etc, can be performed in the digital ecosystem. The paper also enlists numerous points on the importance of e-commerce which are responsible for its development as the new convention. It has enabled the creation and exploitation of new business opportunities, at the same time increasing the say of customers in the development of new products and services. E-commerce has not only augmented the performance of internal business management, but, has also enabled better customer relationships by promoting a business model that is essentially based on information sharing. The accessibility of internet connectivity and other online tools herald a new revolution. SWOT analysis of e-commerce conducted by Awais \& Samin (2012) highlights ubiquity, low operating cost, improved customer interaction and time saving as the unique strengths of e-commerce,but, at the same timeaccentuates upon the necessity for the firms to adapt themselves to the changing environment and innovate constantly to come up with better offerings for customers.

With an increase in the number of players in the B2C segment, competition for the first position is set to intensify, making it imperative for the firms to enhance service quality and to invest in logistics, so as to derive benefits from increase in the disposable income of houseolds, rise in internet subscriptions and infilteration of mobile commerce. (Das \& Ara, 2015). In the face of rising competition, the survival of the firms will depend upon how efficiently they are able to bridge the exsting gaps in e-commerce transactions. The ubiquitous nature of internet has enabled e-commerce to defy geographical boundaries and permeate different markets,so as to elicit demand from sub-urban and rural areas, after having succesfully tapped its potential in metropolitan cities. In anticipation of increasing demand from Tier 2 and 3 cities, many e-commerce firms are undertaking efforts to widen their reach by investing in better infrastructure. In the light of growing number of websites, offering similar goods and services, greater significance is being attributed to Internet Marketing, which shall play an unparalleled role in audience acquisition for e-commerce websites, by displaying the advertisements on search engine result pages and other portals. Internet Marketing shall not only propel ecommerce but will also emerge as an important support tool to brick and mortar stores.(Gangeshwer, 2013).

Apart from Internet Marketing, Deshmukh, Deshmukh \& Thampi (2013) recognise another important development: m-commerce, which they identify as a subset of e-commerce. "Transformation from Ecommerce to M-commerce in Indian Context" reviews the current and potential status of e-commerce and $\mathrm{m}$ commerce in the Indian market, while projecting the latter as the potential future. The paper discerns ubiquity, personalization, flexibility and immediacy as the singular advantages of $\mathrm{m}$-commerce. The authors affirm the idea that smart phone penetration and rise in inetrnet user base, mostly driven by youth, shall propel the growth of e-commerce. Statistical data is used to emphasize that the infrastructure requisite for m-commerce development already exists, however, it is yet to be properly deployed. With mobile penetration providing a boost to digital downloads and enabling cheaper monetary transfers, the need of the hour is to enhance customer confidence by providing them assurance of safety and privacy, which shall accelerate movement towards a cashless economy.

Despite innumerable prospects, the growth of e-commerce in India has not been upto its full potential due to certain challenges that inhibit the growth of firms. The growth of digital commerce in India is impeded by inadequate infrastructure, logistics failure, lack of tax uniformity and declining margins. In the face of intense competition, firms have to pamper the customers with huge discounts, everyday offers and liberal returns policy which proves detrimental to their profits. As against the firms following inventory model, emarketplaces are more adversely affected by subsidies as they have to offer incentives to the seller for listing their products on the website in addition to the humungous discounts and wide range of offers to the customers. The increasing fulfillment costs (includes every cost incurred from the point an order is placed till the time its delivered to the customer.), lack of last mile connectivity in many sub-urban and rural areas and the rising reverse logistics also hinder the the growth of e-commerce firms by resulting in huge loss.(Rina, 2016).

\section{A Literary Analysis}

As noted by Ray (2011) "As a symbol of globalization, e-commerce represents the cutting edge of success in this digital age and it has changed and is still changing the way business is conducted around the world." Developments in internet and web based technologies have narrowed down the differences between traditional and e-marketplaces leading to e-commerce fast becoming the new convention. With all its inherent advantages like cost reduction, access to worldwide markets, better relationship management and transparency of information, e-commerce has a promising future with many growth prospects, especially, in the e-retail industry. A study conducted by ASSOCHAM states that "the size of the e-retail industry is poised to be 10 to 20 billion USD by 2017-2020.". However, to propel the predicted growth it is necessary for the e-commerce firms 
to payappropriate and adequate attention to certain key areas. Some futuristic trends in the growth of ecommerce can be-

I. Omnichannels - The future lies not in a market where traditional brick and mortar stores are dominated by e-commerce websites, but, in a business environment where offline stores are perfectly complemented by their online counterparts. (Numberger \& Renhank, 2005). With the number of online vendors, with similar offerings of goods and services increasing everyday, the consumers are becominglargely fickle with respect to their preferences, turning everytime to the website offering more discounts and offers. In such a scenario, survival becomes difficult and can only be sustained by increasing the number of touch points with the consumers, so as to expand the seller's visibility. In May 2015, India's largest fashion portal, Myntra shut down its desktop website to become an app only marketplace, but, had to relaunch it in June 2016 owing to customer attrition. Thus, the convergence of bricks and clicks projects a more sustainable ecosystem.

II. Niche Businesses - A study conducted by Deloitte, "Future of e-commerce: Uncovering Innovation", notes the rising culture of start-ups focussing on niche areas, that tend to serve everyday purposes of the customers. In the era of giant marketplaces like Amazon and Flipkart, which focus on adding more products to their existing basket, firms like Bluestone, Lenskart, Pepperfry, UrbanClap, OlaCabs etc. target a niche area, so as to offer a unique proposition.

III. Mergers \& Acquisitions- Another emerging trend in the e-commerce market is acquisition of smaller firms by the market leaders, which helps to curb competition and ensures the survival of the fittest. The past years have been marked by significant acquisitions, which have enabled firms like Flipkart, Snapdeal, Ola and others to grow inorganically. WeRead, Letsbuy.com, Myntra are some of the firms acquired by Flipkart. Snapdeal has made around 12 acquisitions since its inception. Similarly, Ola Cabs, BookMyShow, Pepperfry etc. have taken over lesser known players in the same product category to consolidate their position in the market.

IV. Focus on Services -In the light of increasing number of e-commerce firms coming up with similar offerings, services will provide the cutting edge to the firms to improve their performance metrics. Services can act as a differentiating factor for the firms, who can tap into the potential of increasing customer base by serving them better than their competitors. Social Media, while being an important data source and advertising avenue for e-commerce firms, also serves as a platform for the customers to vent out their frustration in case of bad shopping experience, an event which can prove detrimental to the image of the online vendor or marketplace. Firms can avoid the same by ensuring constant order and delivery updates, immediate redressal of grievances, in addition to product quality.

V. Internet Marketing - Internet Marketing has an important role to play, to provide an enhanced customer experience, as well as, to generate and retain more traffic on the website. Attractive design and user friendliness of the website would play key roles in the consolidation of a firm in e-commerce market. "Search engine marketing (SEM) is a form of web advertising that companies use to promote their products and services on search engine results pages."(Gangeshwer, 2013). SEM, which places ads on search engine result pages is evolving as an important customer acquisition strategy. Similarly, companies can make use of effective SEO (Search Engine Optimization) to increase its online visibility and hence, generate more traffic.

VI. Tapping Rural Markets - With the smartphone penetration (through low priced devices) to rural areas, the potential of rural markets cannot be tapped unless it is followed by a penetration of network services. According to "India@Digital.Bharat" Report by BCG and IAMAI, the share of rural in Internet user base will increase in 2018. The rural internet user base is estimated to increase from 60 million in 2014 to 280 million in 2018, growing at a rate of $40 \%$ per annum. In the light of these projections, firms can initiate content development in vernacular languages to effectively exploit the opportunities in rural markets, at the same time improve its logistics capability so as to ensure last mile connectivity.

VII. Better Infrastructure - With a large proportion of the online traffic moving from desktop to mobile, ecommerce firms need to introduce apps that consume less data and light mobile websites that provide a seamless shopping experience to its customers.

VIII. Rise in the share of Digital Payments- Cash on Delivery has forever been the default payment option for most buyers due to convenience and privacy issues. Though, COD has played an important role in driving sales, it has also adversely affected the merchants by adding to the costs and leading to reverse logistics. Firms have tried to curb the use of COD by adding delivery charge and offering additional discounts on the use of digital payments, but the reluctance of the customers to share information owing to security concerns has hindered the growth of digital payments. However, in the aftermath of demonetisation, implemented by the government of India in November 2016, the culture of cashless payments is set to rise: evidenced from the fact that many e-commercefirms reporteda decline in the share 
of COD orders. Demonetisation has forced many customers to switch to credit/debit cards, net banking or mobile wallet, a habit which can be sustained by ensuring secure payments infrastructure.

\section{Conclusion}

The paper provides insight into the evolution of e-commerce in India, while understanding the nitty gritties of its different aspects, with special emphasis on B2C e-commerce: which has shown tremendous growth in the recent years due to increased consumer awareness, investor trust and technological proliferation. The objective was to review the literature available on e-commerce, so as to trace its development in the Indian Economy while isolating its relevant advantages and limitations. The study has also produced certain trends and factors which shall propel further growth in the e-commerce market in India. A sustainable business practice would be to promote e-commerce and m-commerce as complements rather than substitutes to traditional business. The synergies between offline and online businesses will enhance efficiency and result in a more stable existence. The future also entails a scenario which shall witness a rise in niche businesses, as well as, mergers and acquisitions to enable firms to grow inorganically. Firms need to commit themselves to the provision of services and application of internet marketing, to generate and retain larger audience. Through mobile penetration, opportunities are emerging in the rural markets which, cannot be tapped unless followed by a network proliferation, better mobile app infrastructure, content development in local languages and last mile connectivity. Also, in the aftermath of demonetisation, the share of digital payments is expected to rise, to sustain which, firms need to develop more secure payments infrastructure.

\section{References}

[1] Aggarwal, M. (2014, November). Escalating Development of E-Commerce in India. International Journal Of Scientific Research, 3(11), 78-79.

[2] Aulakh, G. (2015, September). Retrieved from http://economictimes.indiatimes.com/industry/banking/finance/banking/alibaba-antfinancial-invest-about-680-million-in-paytm-up-stake-to-40/articleshow/49148651.cms

[3] Awais, M., \& Samin, T. (2012, March). Advanced SWOT Analysis of E-Commerce. International Journal of Computer Science Issues, 9(2), 569-574.

[4] Chanana, N., \& Goele, S. (2012). Future of E-Commerce In India. International Journal of Computing \& Nusiness Research.

[5] Das, D. K., \& Ara, A. (2015, July). Growth of E-Commerce in India. International Journal Of Core Engineering \& Management, 2(4), 25-33.

[6] Deshmukh, S. P., Deshmukh, P., \& Thampi, G. (2013, July). Transformation from E-commerce to M-commerce in Indian Context. International Journal of Computer Science Issues, 10(4), 55-60.

[7] Franco, D. C., \& S, B. R. (2016). Advantages And Challenges Of E-Commerce Customers And Businesses: In Indian Perspective. International Journal of Research - GRANTHAALAYAH, 7-13.

[8] Gangeshwer, D. K. (2013). E-Commerce or Internet Marketing: A Business Review from Indian Context. International Journal of $u$ - and e-Service, Science and Technology, 6, 187-194.

[9] Gunasekaran, A., Marri, H., McGaughey, R., \& Nebhwani, M. (2002). E-commerce and its impact on operations management. International Journal Of Production Economics, 185-197.

[10] Gupta, A. (2014, January). E-Commerce : Role Of E-Commerce In Today's Business. International Journal of Computing and Corporate Research, 4(1).

[11] Mac, R. (2014, October). Retrieved from https://www.google.co.in/amp/www.forbes.com/sites/ryanmac/2014/10/28/softbank-betsbig-on-india-with-627-million-snapdeal-investment/amp/

[12] Mishra, S. V., \& Kotkar, D. S. (2015, February). A Study on Current Status of E-Commerce in India: A Comparative Analysis of Flipkart and Amazon. International Journal of Advance Research in Computer Science and Management Studies, 3(2), $133-137$.

[13] Numberger, S., \& Renhank, C. (2005). The Future of B2C E-Commerce. Electronic Markets, 269-282.

[14] Raghunath, A., \& Panga, M. D. (2013). Problem and Prospects of E-Commerce. International Journal of Research and Development - A Management Review, 2(1), 59-68.

[15] Ray, S. (2011). Emerging Trend of E-Commerce in India: Some Crucial Issues, Prospects and Challenges. Computer Engineering and Intelligent Systems, 18-36.

[16] Rina, D. (2016, March-April). Challenges and Future Scope of E-commerce in India. International Journal of Emerging Trends \& Technology in Computer Science, 5(2), 232-235.

[17] Shankar, S. (2016, May). Retrieved from http://economictimes.indiatimes.com/small-biz/sme-sector/b2b-e-commerce-market-6times-larger-than-b2c-sme-lenders/articleshow/52499816.cms 